EXTENDED REPORT

\title{
Cytokine production in the infrapatellar fat pad: another source of cytokines in knee synovial fluids
}

\author{
T Ushiyama, T Chano, K Inoue, Y Matsusue
}

Ann Rheum Dis 2003;62:108-112

See end of article for authors' affiliations

....................

Correspondence to: Dr T Ushiyama, Department of Orthopaedic Surgery, Shiga University of Medical Science, Seta, Otsu,

520-2192, Japan; usiyama@

belle.shiga-med.ac.jp

Accepted 20 June 2002
Background: Recent studies have shown that adipose tissue is an endocrine organ that releases various cytokines.

Objective: To investigate the production of growth factors and proinflammatory cytokines in infrapatellar fat pad specimens.

Methods: Infrapatellar fat pad tissues were obtained from patients during knee surgery. Protein levels of basic fibroblast growth factor (bFGF), vascular endothelial growth factor (VEGF), tumour necrosis factor (TNF) $\alpha$, and interleukin (IL) 6 in homogenised tissues were measured by an enzyme immunoassay. Gene expressions for those cytokines were examined by reverse transcriptionpolymerase chain reaction (RT-PCR). Localisation of bFGF and VEGF was evaluated by immunohistochemistry and in situ hybridisation.

Results: Infrapatellar fat pads were found to contain various protein levels of bFGF, VEGF, TNF $\alpha$, and IL6. Further, gene expressions for these cytokines were detected by RT-PCR. Immunohistochemistry and in situ hybridisation showed that the expressions of both bFGF and VEGF were localised in immature adipocytes, interstitial undifferentiated mesenchymal cells, and vascular endothelial cells.

Conclusion: The production of bFGF, VEGF, TNF $\alpha$, and IL6 in the infrapatellar fat pad was demonstrated. Although synovial cells and articular chondrocytes are thought to be primary sources of cytokines found in knee synovial fluids, the results suggest that they may also originate from this fat pad.
K nee osteoarthritis (OA) is a common disease among elderly people, with such features as cartilage loss and bone proliferative changes. Although the pathogenesis of knee OA is not clearly understood, both mechanical and metabolic factors are responsible for the disease. ${ }^{1-3}$

In knee synovial fluids, various metabolic factors such as growth factors and proinflammatory cytokines are measurable, and are known to have important roles in cartilage metabolism and, subsequently, OA processes..$^{4-6}$ Because synovial cells and articular chondrocytes express various cytokines, they are thought to be the primary source of cytokines secreted into joint cavities. ${ }^{7-12}$

A characteristic part of the knee joint structure is an infrapatellar fat pad that is composed of constitutional fat tissue, the development of which is dictated by sex hormones. It is located in the space between the patellar tendon, femoral condyle, and tibial plateau, and has a surface covered by a layer of synovial membrane; thus, it is both intra-articular and extrasynovial. The infrapatellar fat pad is also known to be involved in some pathological conditions. ${ }^{13}$

Recently, adipose tissue has been recognised as an endocrine organ that releases cytokines in an endocrine, autocrine, and paracrine manner. ${ }^{14}$ Among various growth factors, basic fibroblast growth factor (bFGF) and vascular endothelial growth factor (VEGF) have been detected in animal adipose tissues as well as a mouse adipocyte cell line. ${ }^{15}{ }^{16}$ In addition, previous reports have shown that adipose tissue is a significant source of endogenous tumour necrosis factor (TNF) $\alpha$ and interleukin (IL) 6 in humans. ${ }^{17} 18$

In view of the above findings, we suggested that the infrapatellar fat pad might be another source of the cytokines found in knee synovial fluids, in addition to synovial cells and articular chondrocytes. Therefore, we investigated the production of cytokines in the infrapatellar fat pad, with special interest given to bFGF and VEGF.

\section{MATERIALS AND METHODS}

\section{Infrapatellar fat pads}

Infrapatellar fat pad tissues were obtained from seven patients ( six women, one man) during knee surgery after informed consent was obtained. The patient ages ranged from 19 to 76 years old (mean 59.6 years). Five had knee OA and two had a ligamentous injury of the knee. During the operation, infrapatellar fat pad tissues were carefully sliced off and immediately preserved in liquid nitrogen and/or neutral buffered formalin.

\section{Synovial fluids of the knee}

From the seven subjects, four synovial fluid specimens were available for cytokine assays (patients 1, 2, 4, and 5). In the other three patients, synovial fluids were either bloody or there was too little to analyse. To remove debris, the synovial fluids were centrifuged at $1000 \mathrm{~g}$ for 10 minutes, and then the supernatant was separated and preserved at $-80^{\circ} \mathrm{C}$.

\section{Enzyme immunoassay (EIA)}

For measurement of protein levels by EIA, the tissues were preserved in liquid nitrogen, then homogenised in phosphate buffered saline (PBS; $100 \mathrm{mg}$ tissue/ml PBS), filtered, and preserved again at $-80^{\circ} \mathrm{C}$ until analysis.

EIA was performed using bFGF, VEGF, TNF $\alpha$, and IL6 kits (Quantikine, Quantikine HS, R\&D Systems, NE, USA) according to the manufacturer's protocols.

\section{RNA extraction}

Total RNA was extracted from the adipose tissues by a standard procedure using a kit (Isogen, Wako Chemical, Osaka, Japan).

Abbreviations: bFGF, basic fibroblast growth factor; EIA, enzyme immunoassay; GAPDH, glyceraldehyde-3-phosphate dehydrogenase; IL, interleukin; OA, osteoarthritis; PBS, phosphate buffered saline; RT-PCR, reverse transcription-polymerase chain reaction; TNF, tumour necrosis factor; VEGF, vascular endothelial growth factor 
Table 1 bFGF, VEGF, TNF $\alpha$, and IL6 protein levels in infrapatellar fat pad tissues and knee synovial fluids from patients with osteoarthritis and ligamentous injury

\begin{tabular}{llllllll}
\hline \multicolumn{7}{c}{ Patient } & No \\
\cline { 2 - 7 } & 1 & 2 & 3 & 4 & 5 & 6 & 7 \\
\hline Disease & OA & OA & OA & OA & OA & Ligamentous injury & Ligamentous injury \\
Age (years) & 68 & 73 & 65 & 70 & 76 & 46 & 19 \\
Sex & Female & Female & Female & Female & Female & Male & Female \\
Infrapatellar fat pad tissue & (pg/g tissue) & & & & \\
bFGF & 3760 & 38800 & 17200 & 13370 & 12700 & 14950 & 5640 \\
VEGF & $<156$ & 554 & 277 & 213 & $<156$ & $<156$ & $<156$ \\
TNF $\alpha$ & 9.5 & 5.4 & $<3.5$ & $<3.5$ & $<3.5$ & 17.4 & 54.3 \\
IL6 & 2.4 & 11.4 & $<1.5$ & 1240 & 12.5 & 4.2 & 2.8 \\
Synovial fluid (pg/ml) & & & & & & - \\
bFGF & 114 & 12.8 & - & 13.1 & 17.7 & - & - \\
VEGF & 2900 & 1516 & - & 3640 & 1364 & - & - \\
TNF $\alpha$ & 1.6 & 1.5 & - & $<0.35$ & $<0.35$ & - & - \\
IL6 & 7.8 & 23.0 & - & 20400 & 238 & - & \\
\hline
\end{tabular}

Lower detection limits of the assay: bFGF 10 (pg/g tissue), 1 (pg/ml); VEGF $156(\mathrm{pg} / \mathrm{g}$ tissue), 15.6

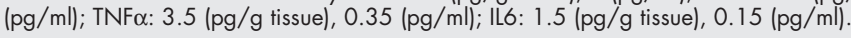

\section{Reverse transcription-polymerase chain reaction (RT-PCR)}

Five infrapatellar fat pad specimens (from patients 1-5) were available for RT-PCR analysis.

To remove genomic DNA contamination before the RT-PCR procedure, each total RNA was treated with RNase-free DNase I (Nippongene, Toyama, Japan) in the presence of RNase inhibitor (Wako chemical) for 15 minutes at $37^{\circ} \mathrm{C}$, followed by proteinase $\mathrm{K}$ digestion, phenol/chloroform extraction, and ethanol precipitation. The RNA was quantified spectrophotometrically at $260 \mathrm{~nm}$.

RT was performed with an RNA PCR kit (TAKARA SHUZO, Otsu, Japan) according to the manufacturer's protocol. RT of RNA into cDNA was performed by incubating $2 \mu \mathrm{g}$ of total RNA with AMV reverse transcriptase, nonamer random primers, dNTP, and RNase inhibitor at $30^{\circ} \mathrm{C}$ for 10 minutes, followed by incubation at $42^{\circ} \mathrm{C}$ for 30 minutes. One microlitre $(100 \mathrm{ng})$ of each cDNA sample from the above extractions was amplified by PCR (GeneAmp System 2400, Perkin Elmer) in a total volume of $20 \mu \mathrm{l}$ using 0.5 units of Ex Taq polymerase (TAKARA SHUZO) with the accompanying buffer, a $200 \mu \mathrm{M}$ dNTP mixture, and $0.2 \mu \mathrm{M}$ each of the specific oligonucleotide primers. The oligonucleotide primers, prepared according to published sequences, were as follows: $\mathrm{bFGF}^{19}{ }^{19} \mathrm{VEGF}^{20} \mathrm{TNF} \alpha$, IL6, ${ }^{21}$ and glyceraldehyde-3-phosphate dehydrogenase (GAPDH). ${ }^{22}$ PCR amplification was performed for 25 to 35 cycles. The amplified products were separated by electrophoresis using $6 \%$ polyacrylamide gels.

\section{Immunohistochemistry}

Adipose tissue specimens, fixed in neutral buffered formalin, were embedded in paraffin and cut into sections $4 \mu \mathrm{m}$ thick. Immunostaining by rabbit antihuman polyclonal antibodies for bFGF and VEGF was performed by the avidin-biotin complex method using a Vectastain ABC kit (Vector laboratories, Burlingame, USA). After deparaffinisation, the sections were successively incubated in each reagent with appropriate PBS washes: $0.3 \%$ hydrogen peroxidase for 30 minutes, normal goat serum for 20 minutes, primary antibody for one hour, biotinyl goat antirabbit antibody for 30 minutes, and avidin-biotin complex for 30 minutes. The reaction was visualised using the chromogen diaminobenzidine (DAKO A/S, Glostrup, Denmark) and the sections were counterstained with methyl green. Rabbit polyclonal antibodies used were as follows: anti-bFGF antibody (FGF-2 (147): sc-79, Santa Cruz Biochemistry, USA) and anti-VEGF antibody (VEGF (A-20): sc-152, Santa Cruz Biochemistry). The working concentration of each primary antibody was $1 \mu \mathrm{g} / \mathrm{ml}$. As a negative control, normal rabbit IgG $(1 \mu \mathrm{g} / \mathrm{ml})$ was used instead of the primary antibodies.

\section{In situ hybridisation}

In situ hybridisation was performed using bFGF-specific or VEGF-specific cRNA probes. The bFGF cDNA (136 bp) and VEGF121 cDNA (516 bp) fragments were obtained from the RT-PCR products, as described above. Both were cloned into a pCR II-TOPO vector (Invitrogen, Groningen, The Netherlands) and linearised, then run-off incorporation of digoxigenin labelled UTP was performed with RNA polymerase using a T7/Sp6 RNA labelling kit (Roche, Basel, Switzerland). The histological sections were treated with $2.5 \mathrm{mg} / \mathrm{ml}$ of pepsin in $0.1 \mathrm{~N} \mathrm{HCl}$ for 30 minutes at $37^{\circ} \mathrm{C}$ and dehydrated in absolute ethanol. The sections were then hybridised overnight with $\mathrm{l}$ $\mathrm{mg} / \mathrm{ml}$ digoxigenin labelled bFGF-specific or VEGF-specific cRNA probes, respectively, in a hybridisation solution at $37^{\circ} \mathrm{C}$. After hybridisation, they were washed three times in $1 \times$ Tris buffered saline containing $0.05 \%$ Tween 20 . Through this step, the reagents were from KREATECH (Amsterdam, The Netherlands) and the protocol was followed according to the manufacturer's instructions. Subsequently, the sections were

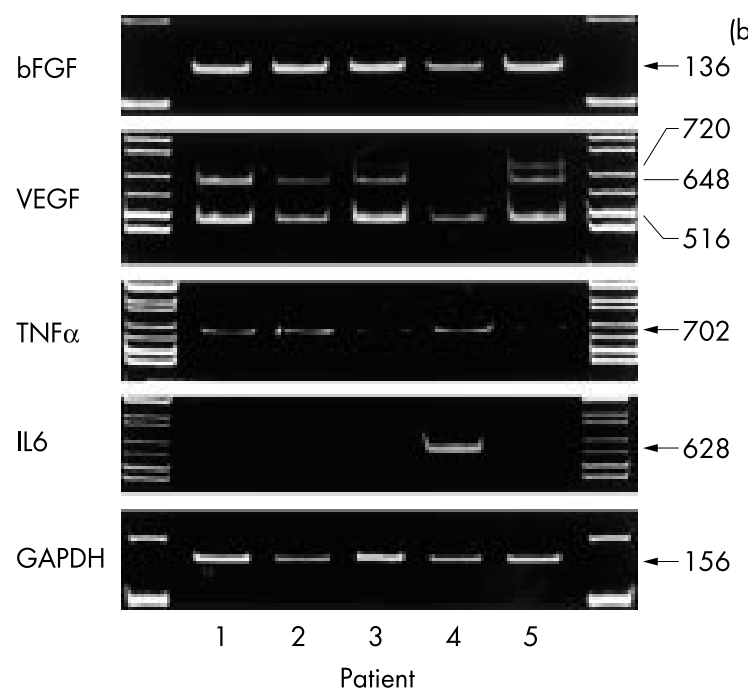

Figure 1 RT-PCR results for bFGF, VEGF, TNF $\alpha$, IL6, and GAPDH in infrapatellar fat pad tissues. Expected sizes of the amplified DNA fragments are shown in the ethidium bromide $6 \%$ polyacrylamide gel electrophoresis images. The number under each panel indicates patient number, whose characteristics are shown in table 1. Amplified fragments of bFGF, the lower three VEGF isoforms (VEGF 121: 516 bp, VEGF 165: 648 bp, VEGF 189: 720 bp), and TNF $\alpha$ were detected in all five specimens, whereas those of IL6 were detected in only one. 

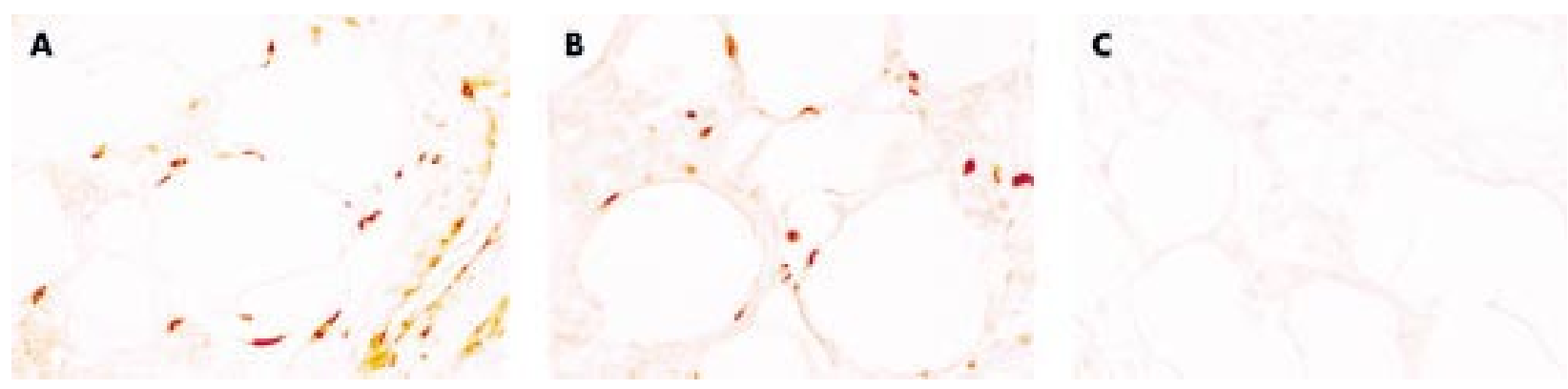

Figure 2 Immunohistochemical staining of infrapatellar fat pad tissues. (A) bFGF, (B) VEGF, (C) normal rabbit lgG. Positive cytoplasmic staining for bFGF and VEGF was detected in relatively immature adipocytes, interstitial undifferentiated mesenchymal cells, and vascular endothelial cells. Original magnification $\times 100$.

incubated with $0.2 \mathrm{mg} / \mathrm{ml}$ anti-digoxigenin mouse IgGl (Roche) for 30 minutes, followed by incubation with biotin-labelled secondary antibody. Finally, the sections were subjected to peroxidase conjugated with streptavidin using a DAKO Universal Quick Stain kit. Peroxidase activity was detected using the chromogen diaminobenzidine (DAKO A/S) and the sections were counterstained with methyl green. A poly-(A) oligo probe supplied by KREATECH was used as the positive control, and negative controls used bFGF-specific or VEGF-specific sense RNA probes.

\section{RESULTS}

Protein levels of bFGF, VEGF, TNF $\alpha$, and IL6 in infrapatellar fat pad and knee synovial fluid samples

Table 1 shows the patient characteristics along with protein levels of bFGF, VEGF, TNF $\alpha$, and IL6 in homogenised adipose tissues by EIA. bFGF was detected in all specimens (mean (SD) 15202 ( 11495$) \mathrm{pg} / \mathrm{g}$ tissue), whereas VEGF was detected in three of the seven patients at 348 (181) pg/g tissue and TNF $\alpha$ in four patients at 21.7 (22) pg/g tissue. Except for one patient with high levels of IL6 (patient 4, $1240 \mathrm{pg} / \mathrm{g}$ tissue), levels of IL6 were generally low (6.7 (4.9) pg /g tissue).

In synovial fluids from four patients, cytokine protein levels were as follows: bFGF 39.4 (49.8) pg/ml, VEGF 2355 (1100) $\mathrm{pg} / \mathrm{ml}$, and TNF $\alpha 1.5(0.11) \mathrm{pg} / \mathrm{ml}$. Levels of IL6 were wide ranging $(7.8-20400 \mathrm{pg} / \mathrm{ml})$. Although the number of specimens was small, there was no significant association of cytokine levels between the fat pads and synovial fluids.

\section{RT-PCR analysis of bFGF, VEGF, TNF $\alpha$, and IL6}

RT-PCR results showed the expected amplified fragments of bFGF, the lower three VEGF isoforms (VEGF121: $516 \mathrm{bp}$, VEGF165: 648 bp, VEGF189: 720 bp), and TNF $\alpha$ in all specimens, whereas those of IL6 were detected in only one of five specimens (fig 1).

\section{Immunohistochemistry for bFGF and VEGF}

Figure 2 shows the results for immunohistochemical staining of adipose tissue. Positive cytoplasmic staining for bFGF and VEGF was detected in relatively immature adipocytes, interstitial undifferentiated mesenchymal cells, and vascular endothelial cells.

\section{In situ hybridisation for bFGF and VEGF}

Positive signals for both bFGF and VEGF were detected in the cytoplasm of relatively immature adipocytes, interstitial undifferentiated mesenchymal cells, and endothelial cells (fig $3)$.

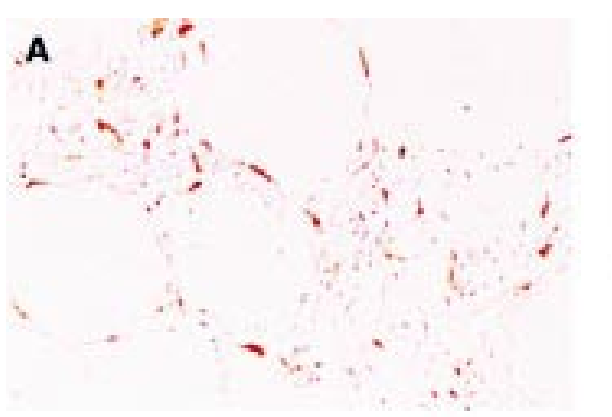

B

D

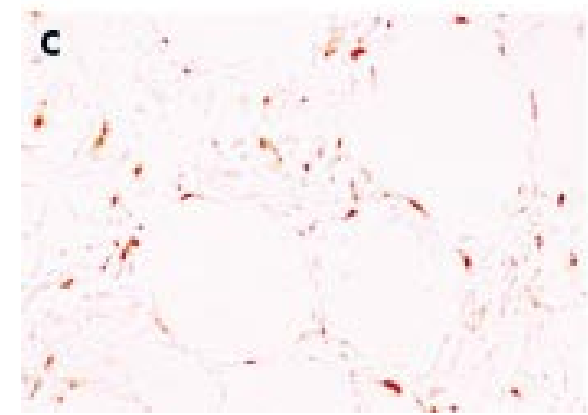

Figure 3 In situ hybridisation results for bFGF and VEGF in infrapatellar fat pad tissues. (A) Anti-sense probe for bFGF, (B) sense probe for bFGF, (C) anti-sense probe for VEGF, (D) sense probe for VEGF. Positive signals for bFGF and VEGF were detected in the cytoplasm of relatively immature adipocytes, interstitial undifferentiated mesenchymal cells, and vascular endothelial cells. Original magnification $\times 50$. 


\section{DISCUSSION}

Our results showed that the infrapatellar fat pad specimens consistently contained bFGF, whereas VEGF was found in some cases, and the proinflammatory cytokines TNF $\alpha$ and IL6 to a smaller extent. The infrapatellar fat pad was found to synthesise these cytokines, though there was no association between PCR results and protein levels. These cytokines were also measurable in knee synovial fluids. Therefore, though synovial cells and articular chondrocytes express these cytokines $^{7-12}$ and are thought to be the primary sources of those found in the joint cavity, our results suggest that the cytokines may also originate from the infrapatellar fat pad.

Although bFGF was present at high concentrations in the fat pad specimens, it is worth noting that the concentration in synovial fluids was significantly reduced. In contrast, only small quantities of VEGF were detected in the fat pad samples, whereas high levels were present in synovial fluids, even in those from patients in whom VEGF was under detectable limits in the fat pad. We also examined the protein levels of bFGF and VEGF in synovial tissues from OA knees, and found a similar distribution of contents as in the fat pad tissues (data not shown). These results suggest that VEGF is the primary secretory agent from these tissues, in contrast with bFGF, which is only secreted in low amounts.

We identified both bFGF and VEGF in immature adipocytes, interstitial mesenchymal cells, and vascular endothelial cells in the infrapatellar fat pad tissues. Yamashita et al reported the expression of bFGF in rat brown adipocyte primary cultures, ${ }^{15}$ while Claffey et al indicated that VEGF was dramatically induced during adipocyte differentiation in a mouse adipocyte cell line. ${ }^{16}$ Our results, together with those of previous studies, suggest that bFGF and VEGF are up regulated during adipocyte differentiation.

The growth factors bFGF and VEGF, both endothelial cell-specific mitogens, have been detected in human OA cartilage. ${ }^{10}{ }^{11}$ Further, the results of other studies have shown that bFGF seems to be a negative regulator of human articular chondrocytes, as it down regulated chondrocyte phenotype and type II collagen expressions, and decreased thymidine and sulphate incorporation, while it also stimulated collagenase 3 production in cultured human OA chondrocytes. ${ }^{23}{ }^{24}$ Recently, it was shown that blood vessel invasion mediated by VEGF is essential for coupling hypertrophic cartilage remodelling, ossification, and endochondral bone formation in growth plate cartilage, ${ }^{2526}$ which is considered to have a relationship with characteristic bone proliferative changes in OA.

On the other hand, proinflammatory cytokines are also involved in cartilage breakdown. For example, TNF $\alpha$ was shown to up regulate matrix metalloproteinase synthesis by chondrocytes under both normal and pathological conditions, and possibly increased IL6 in OA chondrocytes by an autocrine function. ${ }^{12}$

Interestingly, epidemiological studies have consistently found that obesity is a major risk factor for the development and progression of knee OA. ${ }^{1-3} 27$ If adiposity has a role in knee OA, not only by mechanical stress but also by obesity linked metabolic factors, intracapsular fat tissue may directly affect this "obesity sensitive joint".

In conclusion, we detected the production of bFGF, VEGF , TNF $\alpha$, and IL6 in infrapatellar fat pad specimens. A mechanism may exist whereby the infrapatellar fat pad modulates chondrocyte metabolism through cytokine production in the joint fluids, though there is no in vivo evidence that cytokines are released from fat pad tissues. Furthermore, the possible contribution of fat pad derived cytokines in the pathogenesis of OA remains to be addressed, because there was no association between any of the cytokines measured and $\mathrm{OA}$ and/or ligamentous injury seen in our data. Thus, the contribution of infrapatellar fat pad derived cytokines to the process of knee OA should be elucidated in the future.

\section{ACKNOWLEDGEMENTS}

We thank the staff of the Department of Surgical Pathology, Shiga University of Medical Science, for their kind support.

Supported in part by a grant-in-aid for scientific research (10671355) from the Ministry of Education, Science, and Culture of Japan.

\section{Authors' affiliations}

T Ushiyama, K Inove, Y Matsusue, Department of Orthopaedic

Surgery, Shiga University of Medical Science, Seta, Otsu, Japan

T Chano, Department of Surgical Pathology, Shiga University of Medical Science, Seta, Otsu, Japan

\section{REFERENCES}

1 Felson DT. Osteoarthritis: new insights. Part 1: The disease and its risk factors. Ann Intern Med 2000;133:635-46.

2 Hochberg MC, Lethbridge-Cejku M, Scott WW, Reichle R, Plato CC, Tobin JD. The association of body weight, body fatness and body fat distribution with osteoarthritis of the knee: data from the Baltimore Longitudinal Study of Aging. J Rheumatol 1995;22:488-93

3 Hart DJ, Doyle DV, Spector TD. Association between metabolic factors and knee osteoarthritis in women: the Chingford Study. J Rheumatol 1995:22:1118-23.

4 Cameron ML, Fu FH, Paessler HH, Schneider M, Evans CH. Synovial fluid cytokine concentrations as possible prognostic indicators in the ACL-deficient knee. Knee Surg Traumatol Arthrosc 1994;2:38-44.

5 Bottomley MJ, Webb NJA, Watson CJ, Holt L, Bukhari M, Denton J. Placenta growth factor (PIGF) induces vascular endothelial growth factor (VEGF) secretion from mononuclear cells and is co-expressed with VEGF in synvial fluid. Clin Exp Immunol 2000; 1 19:182-8.

6 Manicourt D-H, Poilvache P, van Egeren A, Devogelaer J-P, Lenz M-E, Thonar EJ-MA. Synovial fluid levels of tumor necrosis factor $\alpha$ and oncostatin $M$ correlate with levels of markers of the degradation of crosslinked collagen and cartilage aggrecan in rheumatoid arthritis but not in osteoarthritis. Arthritis Rheum 2000;43:281-8.

7 Qu Z, Huang XN, Ahmadi P, Andresevic J, Planck SR, Hart CE, et al. Expression of basic fibroblast growth factor in synovial tissue from patients with rheumatoid arthritis and degenerative joint disease. Lab lnvest 1995;73:339-46

8 Ikeda M, Hosoda Y, Hirose S, Okada Y, Ikeda E. Expression of vascular endothelial growth factor isoforms and their receptors Flt-1, KDR, and neuropilin-1 in synovial tissues of rheumatoid arthritis. J Pathol 2000;191:426-33.

9 Schlaak JF, Schwarting A, Knolle P, Meyer zum Buschenfelde KH, Mayet W. Effects of Th1 and Th2 cytokines on cytokine production and ICAM-1 expression on synovial fibroblasts. Ann Rheum Dis 1995:54:560-5.

10 Uchino M, Izumi T, Tominaga T, Wakita R, Minehara H, Sekiguchi M, et al. Growth factor expression in the osteophytes of the human femoral head in osteoarthritis. Clin Orthop 2000;377:1 19-25.

11 Pufe T, Petersen W, Tillmann B, Mentlein R. The splice variants VEGF 121 and VEGF ${ }_{189}$ of the angiogenic peptide vascular endothelial growth factor are expressed in osteoarthritic cartilage. Arthritis Rheum 2001;44:1082-8.

12 Tetlow LC, Adlam DJ, Woolley DE. Matrix metalloproteinase and proinflammatory cytokine production by chondrocytes of human osteoarthritic cartilage: association with degenerative changes. Arthrtiis Rheum 2001;44:585-94.

13 Magi M, Branca A, Bucca C, Langerame V. Hoffa disease. Ital J Orthop Traumatol 1991;17:211-16

14 Mohamed-Ali V, Pinkney JH, Coppack SW. Adipose tissue as an endocrine and paracrine organ. Int J Obesity 1998;22:1145-58.

15 Yamashita H, Oh-ishi S, Kizaki T, Nagasawa J, Saitoh D, Ohira Y, ef al. Insulin stimulates the expression of basic fibroblast growth factor in rat brown adipocyte primary culture. Eur J Cell Biol 1995;68:8-13.

16 Claffey KP, Wilkison WO, Spiegelman BM. Vascular endothelial growth factor: regulation by cell differentiation and activated second messenger pathways. J Biol Chem 1992;267:16317-22.

17 Hotamisligil GS, Arner P, Caro JF, Atkinson RL, Spiegelman BM. Increased adipose tissue expression of tumor necrosis factor- $\alpha$ in human obesity and insulin resistance. J Clin Invest 1995:95:2409-15.

18 Mohamed-Ali V, Goodrick S, Rawesh A, Katz DR, Miles JM, Yudkin JS et al. Subcutaneous adipose tissue releases interleukin-6, but not tumor necrosis factor- $\alpha$, in vivo. J Clin Endocrinol Metab 1997;82:4196-200.

19 Cronauer MV, Stadlmann S, Klocker H, Abendstein B, Eder IE, Rogatsch $\mathrm{H}$, et al. Basic fibroblast growth factor synthesis by human peritoneal mesothelial cells: induction by interleukin-1. Am J Pathol 1999; 155: 1977-84

20 Dankbar B, Padro T, Leo R, Feldmann B, Kropff M, Mesters RM, et al. Vascular endothelial growth factor and interleukin-6 in paracrine tumor-stromal cell interactions in multiple myeloma. Blood 2000;95:2630-6.

21 Butch AW, Chung G-H, Hofmann JW, Nahm MH. Cytokine expression by germinal center cells. J Immunol 1993; 150:39-47.

22 Tang P-Z, Gannon M, Andrew A, Miller D. Evidence for oestrogenic regulation of heat shock protein expression in human endometrium and steroid-responsive cell lines. Eur J Endocrinol 1995;133:598-605. 
23 Posever J, Phillips FM, Pottenger LA. Effects of basic fibroblast growth factor, transforming growth factor-beta 1, insulin-like growth factor-1, and insulin on human osteoarthritic articular cartilage explants. J Orthop Res 1995; 13:832-7.

24 Tardif G, Pelletier JP, Dupuis M, Geng C, Cloutier JM, Martel-Pelletier J. Collagenase 3 production by human osteoarthritic chondrocytes in response to growth factors and cytokines is a function of the physiologic state of the cells. Arthritis Rheum 1999;42:1 147-58.
25 Gerber HP, Vu TH, Ryan AM, Kowalski J, Werb Z, Ferrara N. VEGF couples hypertrophic cartilage remodeling, ossification and angiogenesis during endochondral bone formation. Nat Med 1999;5:623-8.

26 Carlevaro MF Cermelli S Cancedda R Cancedda FD. Vascular endothelial growth factor (VEGF) in cartilage neovascularization and chondrocyte differentiation: auto-paracrine role during endochondral bone formation. J Cell Sci 2000; 1 13:59-69.

27 Felson DT. Does excess weight cause osteoarthritis and, if so, why? Ann Rheum Dis 1996;55:668-70.

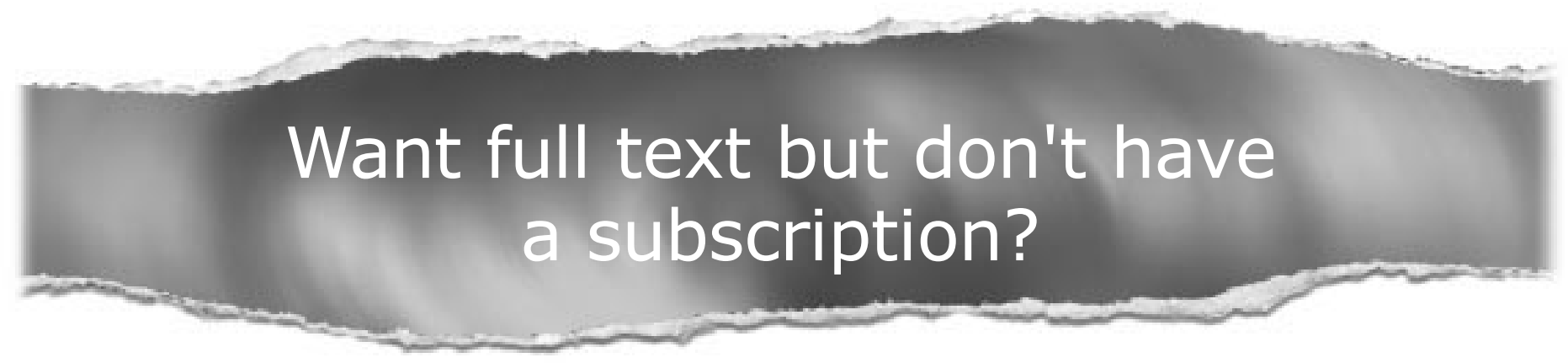

\section{Pay per view}

For just $\$ 8$ you can purchase the full text of individual articles using our secure online ordering service. You will have access to the full text of the relevant article for 48 hours during which time you may download and print the pdf file for personal use.

www.annrheumdis.com 